\title{
ANÁLISE DE CRESCIMENTO E FATORES CLIMÁTICOS NA ESTAQUIA DA PITAIEIRA [Hylocereus undatus (Haw.) Britton \& Rose] TRATADAS COM CITOCININA BAP
}

\author{
Fabio Ferreira Cruvinel ${ }^{1 *}$, Ivan Marcos Rangel Junior ${ }^{2}$, Luiz Aurélio Peres Martelleto ${ }^{3}$, \\ Marco Antonio da Silva Vasconcellos ${ }^{3}$
}

\footnotetext{
${ }^{1}$ Doutorando do Programa de Pós-Graduação em Fitotecnia. Universidade Federal Rural do Rio de Janeiro, Seropédica (RJ). Bolsista CNPq - Brasil *Email: fabiofcruvinel@uol.com.br

${ }^{2}$ Mestrando do Programa de Pós-Graduação em Fitotecnia. Universidade Federal Rural do Rio de Janeiro, Seropédica (RJ).

${ }^{3}$ Professor Doutor da Universidade Federal Rural do Rio de Janeiro. Departamento de Fitotecnia, Seropédica (RJ)
}

RESUMO: A análise quantitativa do crescimento vegetal fornece informações importantes sobre o desenvolvimento de frutíferas de interesse econômico. A técnica consiste em mensurações periódicas da biomassa ou caracteres não destrutivos ao longo do tempo. A correlação das taxas de crescimento com fatores climáticos descreve o comportamento do vegetal frente às condições ambientais. Neste trabalho utilizou-se a abordagem não destrutiva da análise quantitativa do crescimento vegetal para obter e examinar as taxas de crescimento na estaquia da pitaia tratadas com 0 e 100 mg. $\mathrm{L}^{-1}$ de citocinina 6benzilaminopurina (BAP), em experimento com delineamento estatístico inteiramente casualizado (DIC) com parcelas subdivididas no tempo (14 medições semanais) com quatro repetições e cinco estacas por repetição, verificando o incremento em tamanho $(\mathrm{cm})$ da soma do comprimento dos cladódios ao longo do tempo. As brotações foram medidas com trena milimétrica e a área foliar foi calculada pelo volume dos cladódios considerados para cálculo como prismas geométricos. A obtenção das taxas de crescimento vegetal foi realizada pelo método funcional. Os dados climáticos foram obtidos na Estação Automática Ecologia em Seropédica-RJ. Foram calculadas as correlações de Pearson dos dados climáticos com as taxas de crescimento obtidas. A análise estatística foi feita dos dados primários indicando diferenças entre o crescimento de estacas tratadas com BAP e a testemunha. As taxas de crescimento mostraram-se ajustadas com os dados originais. Houve correlação negativa significativa entre as taxas de crescimento e os dados de Radiação do período das $19 \mathrm{~h}$ (22 h UTC).

Palavras-chave: Taxas de crescimento. Radiação solar. Cactácea.

\section{GROWTH ANALYSIS AND CLIMATIC FACTORS IN PITAYA [Hylocereus undatus (Haw.) Britton \& Rose] CUTTINGS TREATED WITH CYTOCININ BAP}

ABSTRACT: Quantitative plant growth analysis can provide important information on the development of fruit of economic interest. The technique consists of periodic measurements of biomass or non-destructive characters over time. The correlation of growth rates with

Cultura Agronômica, Ilha Solteira, v.26, n.4, p.657-670, 2017 
climatic factors describes the behavior of the vegetable against environmental conditions. In this work the non-destructive approach of the quantitative analysis of the plant growth was used to analyze the growth rates of the pitaia cuttings inoculated with 0 and $100 \mathrm{mg} . \mathrm{L}^{-1}$ of cytocinin-6-benzylaminopurine (BAP), in an experiment with a split plot in time design (14 weekly measurements) completely randomized with four replicates and five cuttings per repetition, verifying the increase in size $(\mathrm{cm})$ of the sum of cladodes length over time. Sprouts were measured with millimeter and the leaf area was calculated by the volume of cladodes considered as geometrical prism. Calculation of growth rates was performed using the functional method. The climatic data were obtained from the Automatic Station Ecologia in Seropédica-RJ. The Pearson correlations of the climatic data with the obtained growth rates were calculated. Statistical analysis was done on the primary data indicating differences between the growth of cuttings inoculated with BAP and the control. The growth rates were adjusted with the original data. There was a significant negative correlation between growth rates and radiation data from the $19 \mathrm{~h}$ period ( $22 \mathrm{~h}$ UTC).

Key words: Growth rates. Solar radiation. Cactacea.

\section{INTRODUÇÃO}

A análise quantitativa de crescimento vegetal é uma ferramenta que permite analisar a adaptação climática, a sociologia de plantas, o efeito do manejo e o desenvolvimento da produção vegetal por meio da comparação das taxas de crescimento. Para determinação das taxas de crescimento são feitas mensurações da massa seca ou outras características não destrutivas das plantas como, por exemplo, comprimento, volume ou peso fresco e da área ou volume do órgão responsável pela fotossíntese (CARDOSO et al., 2006; ARAÚJO; ROSSIELLO, 2013; PEDULA et al., 2016).

A pitaieira (Hylocereus spp) é uma cactácea epífita natural de sub-bosque, produz frutos comestíveis que são apreciados por suas propriedades digestivas como a presença de fibras que facilitam o trânsito intestinal e suas características nutracêuticas com ênfase na ação antioxidante dos fenóis presentes em suas sementes e epicarpo. A espécie Hylocereus undatus (Haw.) Britton \& Rose, que possui casca de coloração vermelha e polpa branca, é umas das principais espécies cultivadas com grande aceitação pelo mercado consumidor por causa de sua aparência escamosa exuberante e por sua palatabilidade (ORTIZHERNANDEZ; CARRILO-SALAZAR, 2012; MIZRAHI, 2014; SILVA et al., 2017).

Observa-se carência em trabalhos utilizando a análise de crescimento vegetal para analisar o desenvolvimento da pitaieira, utilização essa que pode elucidar aspectos como a fenologia vegetativa e reprodutiva e comportamento dessa cactácea ante aos fatores ambientais (MIZRAHI, 2014; ALMEIDA et al., 2016).

As condições climáticas são primordiais para o sucesso de plantações comerciais de pitaia. Sabe-se que a pitaieira é sensível a elevadas intensidades luminosas, altas 
temperaturas, fotoperíodo sendo que altas temperaturas aliadas a altas intensidades luminosas podem causar injúrias aos cladódios desde cloroses podendo evoluir para danos necróticos (NERD et al., 2002; ZEE et al., 2004; CAVALCANTE et al., 2011; JIANG et al., 2012; SILVA et al., 2015; CHANG et al., 2016).

A propagação da pitaieira se faz por via vegetativa por meio de estaquia dos cladódios inteiros ou segmentados. Com a finalidade de acelerar o processo de rizogênese e emissão de brotações adventícias utilizam-se fitorreguladores. Na estaquia da pitaieira o uso de auxinas já é bem relatado, porém, estudos dos efeitos de citocininas na propagação de pitaias concentram-se no uso da cultura de tecidos in vitro sendo pouco relatado o efeito de citocininas na indução de brotações na estaquia desta cactácea, uso esse que pode promover o maior número de mudas em menores períodos, favorecendo programas de introdução dessa cultura. As citocininas aplicadas de forma exógenas atuam no balanço fito-hormonal favorecendo a citocinese e consequente maior produção de tecidos de parte aérea. Dentre as citocininas mais utilizadas para esse fim está a 6-benziloaminopurina (BAP) (ORTIZHERNANDEZ; CARRILO-SALAZAR, 2012; NUNES et al., 2014; ALMEIDA et al., 2016).

Diante do exposto, objetivou-se com esse trabalho avaliar a análise quantitativa de crescimento vegetal com abordagem não destrutiva no crescimento de mudas de pitaia, produzidas por estaquia com aplicação da citocinina BAP (6-benzilaminopurina) e sua correlação com os fatores climáticos.

\section{MATERIAL E MÉTODOS}

O experimento foi conduzido em casa de vegetação no Setor de Olericultura do Departamento de Fitotecnia, do Instituto de Agronomia da Universidade Federal Rural do Rio de Janeiro, localizado no município de Seropédica-RJ, com $33 \mathrm{~m}$ de altitude, situado a $22^{\circ} 45^{\prime} \mathrm{S}, 43^{\circ} 41^{\prime}$ W. O clima da região é do tipo Aw, segundo a classificação de Köppen. O experimento foi implantado no dia 10 de outubro de 2015.

Cladódios de $H$. undatus foram selecionados de plantas matrizes em boas condições sanitárias provenientes da Fazendinha Agroecológica em Seropédica-RJ. Segmentaram-se os cladódios, de $7 \pm 2 \mathrm{~cm}$ de diâmetro em estacas de $20 \mathrm{~cm}$ de comprimento da parte central de cada cladódio.

O experimento foi conduzido em canteiro com dimensões de 3,0 metros $(\mathrm{m})$ de comprimento, $0,80 \mathrm{~m}$ de largura e $0,30 \mathrm{~m}$ de profundidade. $\mathrm{O}$ canteiro foi preenchido com substrato contendo areia misturada a esterco bovino na proporção 1:1 em volume. Foi feita a caracterização física e química do substrato segundo metodologia descrita pela Embrapa (2005) listados na Tabela 1.

As estacas de pitaia foram tratadas com solução de citocinina BAP (6benzilaminopurina) por imersão de $1 \mathrm{~cm}$ da parte apical dos cladódios por 24 horas como

Cultura Agronômica, Ilha Solteira, v.26, n.4, p.657-670, 2017 
sugerido por Shimomura e Fujihara (1980). O BAP utilizado foi da marca VETEC calibrado nas concentrações de 0 e 100 mg. $\mathrm{L}^{-1}$ em água destilada com adição de cinco gotas de $\mathrm{NaOH}$ (1M) para facilitar a diluição.

Tabela 1. Características químicas e físicas do substrato utilizado na estaquia de pitaia inoculadas com 0 (testemunha) e $100 \mathrm{mg} . \mathrm{L}^{-1}$ de BAP.

\begin{tabular}{ccc}
\hline Parâmetros Químicos & Unidade & Valor \\
\hline $\mathrm{C}_{\text {total }}$ & & 61,1 \\
$\mathrm{~N}_{\text {total }}$ & & 2,2 \\
$\mathrm{P}_{\text {total }}$ & $\mathrm{g} \mathrm{K}^{-1}$ & 0,83 \\
$\mathrm{~K}_{\text {total }}$ & & 1,17 \\
$\mathrm{Ca}$ total & & 1,51 \\
$\mathrm{Mg}$ total & & 1,63 \\
\hline Parâmetros Físicos & Unidade & Valor \\
\hline Densidade aparente & $\mathrm{Kg} \cdot \mathrm{m}^{-3}$ & 1070 \\
Densidade de partículas & $\mathrm{Kg} \cdot \mathrm{m}^{-3}$ & 2470 \\
Microporosidade & $\%$ & 49,65 \\
Macroporosidade & $\%$ & 6,92 \\
Capacidade de retenção & $\mathrm{mL} .50 . \mathrm{cm}^{-3}$ & 49,65 \\
de água &
\end{tabular}

A estaquia foi realizada no canteiro na profundidade de $1 \mathrm{~cm}$ como recomenda por Marques et al. (2012). Fez-se o sombreamento do canteiro com telado reduzindo a intensidade luminosa em 50\% como recomendado por Chang et al. (2016). Capinas manual e irrigação com 10 litros água foram realizadas semanalmente.

As medições semanais da soma do comprimento das brotações foram realizadas com trena milimétrica. Os cladódios na pitaia são os órgãos fotossintetizantes e o seu volume neste trabalho foi considerado como Área Foliar (AF) mensurada considerando-os como prismas geométricos.

Os dados climáticos de radiação solar global do período das 19 h (22 h UTC), listados na Tabela 2, foram obtidos da Estação Meteorológica Automática Ecologia Agrícola em Seropédica-RJ, junto ao Instituto Nacional de Meteorologia (INMET) do período de condução do experimento (10 de outubro de 2015 a 17 de janeiro de 2016).

O delineamento utilizado foi inteiramente casualizado (DIC), com parcelas subdivididas no tempo (14 medições semanais) destes dois tratamentos (testemunha com 0 mg. $\mathrm{L}^{-1}$ e tratadas com $100 \mathrm{mg} . \mathrm{L}^{-1}$ de BAP) com quatro repetições e cinco estacas por repetição. Os dados primários da soma de comprimento dos cladódios de pitaia foram submetidos à análise de variância para inferir a significância das curvas das taxas de crescimento como postulado por Araújo (2003). Foi realizada avaliação da homogeneidade das variâncias dos erros dos dados primários pelo Teste de Bartlett e da normalidade pelo Teste de Shapiro-Wilk.

Cultura Agronômica, Ilha Solteira, v.26, n.4, p.657-670, 2017 
Tabela 2. Radiação solar global do período das 19 h (22 h UTC) em KJ/m² durante a realização do experimento.

\begin{tabular}{cccccccccc}
\hline Dia & Valor & Dia & Valor & Dia & Valor & Dia & Valor & Dia & Valor \\
\hline $10 / 10 / 15$ & 0,0 & $30 / 10 / 15$ & 0,0 & $19 / 11 / 15$ & 14,7 & $9 / 12 / 15$ & 14,8 & $29 / 12 / 15$ & 44,7 \\
$11 / 10 / 15$ & 0,0 & $31 / 10 / 15$ & 0,0 & $20 / 11 / 15$ & 7,2 & $10 / 12 / 15$ & 13,7 & $30 / 12 / 15$ & 46,4 \\
$12 / 10 / 15$ & 0,0 & $1 / 11 / 15$ & 0,0 & $21 / 11 / 15$ & 9,2 & $11 / 12 / 15$ & 8,9 & $31 / 12 / 15$ & 40,3 \\
$13 / 10 / 15$ & 0,0 & $2 / 11 / 15$ & 0,0 & $22 / 11 / 15$ & 10,3 & $12 / 12 / 15$ & 1,6 & $1 / 1 / 16$ & 5,9 \\
$14 / 10 / 15$ & 0,0 & $3 / 11 / 15$ & 0,0 & $23 / 11 / 15$ & 0,0 & $13 / 12 / 15$ & 2,1 & $2 / 1 / 16$ & 4,8 \\
$15 / 10 / 15$ & 0,0 & $4 / 11 / 15$ & 0,3 & $24 / 11 / 15$ & 6,1 & $14 / 12 / 15$ & 21,5 & $3 / 1 / 16$ & 12,2 \\
$16 / 10 / 15$ & 0,0 & $5 / 11 / 15$ & 0,2 & $25 / 11 / 15$ & 2,2 & $15 / 12 / 15$ & 48,4 & $4 / 1 / 16$ & 31,6 \\
$17 / 10 / 15$ & 0,0 & $6 / 11 / 15$ & 0,1 & $26 / 11 / 15$ & 2,4 & $16 / 12 / 15$ & 51,6 & $5 / 1 / 16$ & 89,9 \\
$18 / 10 / 15$ & 0,0 & $7 / 11 / 15$ & 0,0 & $27 / 11 / 15$ & 10,8 & $17 / 12 / 15$ & 15,4 & $6 / 1 / 16$ & 106,0 \\
$19 / 10 / 15$ & 0,0 & $8 / 11 / 15$ & 0,1 & $28 / 11 / 15$ & 10,7 & $18 / 12 / 15$ & 69,0 & $7 / 1 / 16$ & 70,1 \\
$20 / 10 / 15$ & 0,0 & $9 / 11 / 15$ & 0,9 & $29 / 11 / 15$ & 2,4 & $19 / 12 / 15$ & 56,8 & $8 / 1 / 16$ & 69,8 \\
$21 / 10 / 15$ & 0,0 & $10 / 11 / 15$ & 4,9 & $30 / 11 / 15$ & 2,5 & $20 / 12 / 15$ & 21,1 & $9 / 1 / 16$ & 56,4 \\
$22 / 10 / 15$ & 0,0 & $11 / 11 / 15$ & 5,2 & $1 / 12 / 15$ & 0,7 & $21 / 12 / 15$ & 33,9 & $10 / 1 / 16$ & 13,7 \\
$23 / 10 / 15$ & 0,0 & $12 / 11 / 15$ & 1,1 & $2 / 12 / 15$ & 0,0 & $22 / 12 / 15$ & 58,6 & $11 / 1 / 16$ & 26,6 \\
$24 / 10 / 15$ & 0,0 & $13 / 11 / 15$ & 3,5 & $3 / 12 / 15$ & 2,9 & $23 / 12 / 15$ & 57,3 & $12 / 1 / 16$ & 1,6 \\
$25 / 10 / 15$ & 0,0 & $14 / 11 / 15$ & 5,7 & $4 / 12 / 15$ & 0,3 & $24 / 12 / 15$ & 59,7 & $13 / 1 / 16$ & 9,7 \\
$26 / 10 / 15$ & 0,0 & $15 / 11 / 15$ & 0,0 & $5 / 12 / 15$ & 4,5 & $25 / 12 / 15$ & 82,3 & $14 / 1 / 16$ & 16,2 \\
$27 / 10 / 15$ & 0,0 & $16 / 11 / 15$ & 0,0 & $6 / 12 / 15$ & 5,3 & $26 / 12 / 15$ & 76,4 & $15 / 1 / 16$ & 5,0 \\
$28 / 10 / 15$ & 0,0 & $17 / 11 / 15$ & 3,4 & $7 / 12 / 15$ & 4,5 & $27 / 12 / 15$ & 31,5 & $16 / 1 / 16$ & 29,2 \\
$29 / 10 / 15$ & 0,6 & $18 / 11 / 15$ & 4,3 & $8 / 12 / 15$ & 16,5 & $28 / 12 / 15$ & 65,2 & $17 / 1 / 16$ & 34,6 \\
\hline
\end{tabular}

Para a análise quantitativa de crescimento não destrutiva foi utilizado o método funcional e a variável destrutiva massa seca (W) foi substituída pelo comprimento das brotações (C). Os dados originais do comprimento das brotações e da área foliar (volume dos cladódios) foram linearizados utilizando expressões polinomiais do segundo grau pelo método dos quadrados mínimos de seus logaritmos neperianos como preconizado por Hunt (1982) e Araújo (2003), no modelo:

$$
\ln \mathrm{Y}=a+b \mathrm{~T}+c \mathrm{~T}^{2}
$$

onde: $\ln \mathrm{Y}=$ logaritmo neperiano de $\mathrm{Y}$ onde $\mathrm{Y}$ expressa ou a soma do comprimento das brotações (C) ou da área foliar (volume dos cladódios); a, b e c= coeficientes resultantes do ajuste da curva de $\ln \mathrm{Y} ; \mathrm{T}=$ Tempo.

As seguintes taxas de crescimento foram calculadas: taxa de crescimento relativo (TCR), taxa de crescimento absoluto (TCA) e taxa de assimilação líquida (TAL) utilizando os modelos postulados por Araújo e Rossiello (2013).

Neste trabalho a taxa de crescimento absoluto (TCA) exprime o aumento de tamanho dos novos cladódios de pitaia ao longo do tempo, a taxa de crescimento relativo (TCR) reflete o aumento do tamanho dos cladódios por unidade de comprimento de cladódios préexistentes e a taxa de assimilação líquida (TAL) expressa à taxa de produção do 
comprimento das brotações da pitaia, sendo considerada uma estimativa da atividade fotossintética dos cladódios, representando o balanço liquido entre os ganhos fotossintéticos menos as perdas respiratórias (HUNT, 1982; BENICASA, 2003).

Foram realizados os cálculos dos coeficientes de correlação de Pearson entre as taxas de crescimento e os dados climáticos e da radiação solar global do período das $19 \mathrm{~h}(22 \mathrm{~h}$ UTC) e apresentadas às correlações significativas pelo teste t de Student.

\section{RESULTADOS E DISCUSSÃO}

A análise de variância do comprimento das brotações mostrou diferença significativa $(\mathrm{p}<0,01)$ entre a testemunha e as estacas tratadas com $100 \mathrm{mg} . \mathrm{L}^{-1}$ de BAP. Então, em analogia ao postulado por Araújo (2003), verificaram-se diferenças no comportamento das taxas de crescimento ao longo do tempo, refletindo essas diferenças nas suas curvas, justificando-se suas apresentações e análises.

\section{Ajustes das regressões polinomiais dos dados originais}

Os coeficientes do segundo grau dos dados transformados em seus logaritmos neperiano da soma do comprimento das brotações e da área foliar são apresentados na Tabela 3. Os valores de $\mathrm{R}^{2}$ dos modelos variaram de 0,962 a 0,993 para os dados de soma de comprimento das brotações e área foliar, indicando um adequado ajuste aos dados primários.

Tabela 3. Coeficientes das regressões polinomiais de segundo grau $\left(\ln Y=a+b T+c T^{2}\right)$ ajustados aos dados primários da soma do comprimento das brotações (C) e área foliar (AF) das estacas de pitaia inoculadas com 6-benziloaminopurina (BAP).

\begin{tabular}{lcc}
\hline \multicolumn{2}{c}{ Comprimento das Brotações $(\mathrm{C})$} \\
\hline Coeficientes & $0 \mathrm{mg} \cdot \mathrm{L}^{-1} \mathrm{BAP}$ & $100 \mathrm{mg} \cdot \mathrm{L}^{-1} \mathrm{BAP}$ \\
\hline $\mathrm{a}$ & $-1,717$ & $-15,806$ \\
$\mathrm{~b}$ & 0,0986 & 2,2104 \\
$\mathrm{c}$ & 0,0191 & 0,0051 \\
\hline $\mathrm{R}^{2}$ & 0,993 & 0,962 \\
\hline & & \\
\hline $\mathrm{a}$ & $-0,0103$ & $-0,1005$ \\
$\mathrm{~b}$ & 0,0006 & 0,0141 \\
$\mathrm{c}$ & 0,0001 & 0,00003 \\
\hline $\mathrm{R}^{2}$ & 0,993 & 0,962 \\
\hline
\end{tabular}

O gráfico do modelo do crescimento das brotações é apresentado na Figura 1. Nota-se que os cladódios inoculados com $100 \mathrm{mg} . \mathrm{L}^{-1}$ apresentaram um comportamento de crescimento das brotações adventícias maior que a testemunha $\left(0 \mathrm{mg} . \mathrm{L}^{-1}\right)$ no período.

Cultura Agronômica, Ilha Solteira, v.26, n.4, p.657-670, 2017 


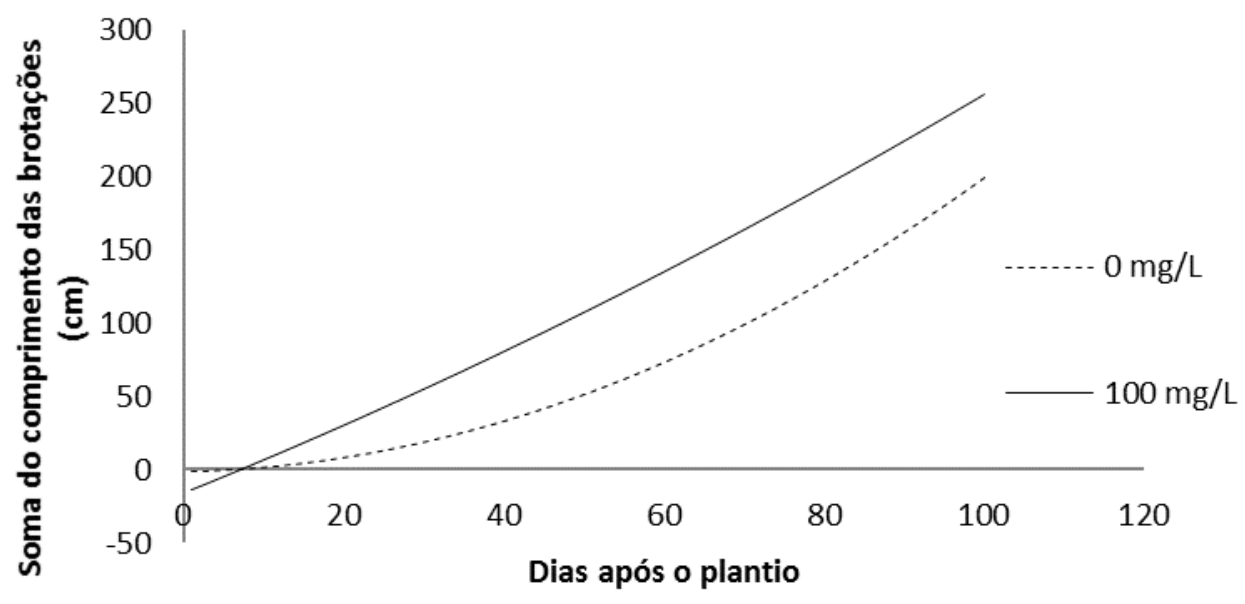

Figura 1. Incremento diário da soma do comprimento das brotações adventícias dos cladódios inoculados com 0 (testemunha) e $100 \mathrm{mg} \cdot \mathrm{L}^{-1}$.

Esses dados corroboram com os resultados de Shimomura e Fujuhara (1980), que aplicaram doses de citocinina benziladenina (BA) e verificaram maior número de brotações e maiores brotações na estaquia de $H$. trigonus. Os resultados confirmam ainda o efeito positivo da citocinina BAP na citocinese e alongamento celular (PIMENTEL, 1998; BARRUETO CID, 2000; TAIZ; ZEIGER, 2004).

O gráfico do incremento diário da área foliar é apresentado na Figura 2. Nota-se o mesmo padrão de desenvolvimento das estacas inoculadas com BAP e em relação à testemunha $\left(0 \mathrm{mg} \cdot \mathrm{L}^{-1}\right)$.

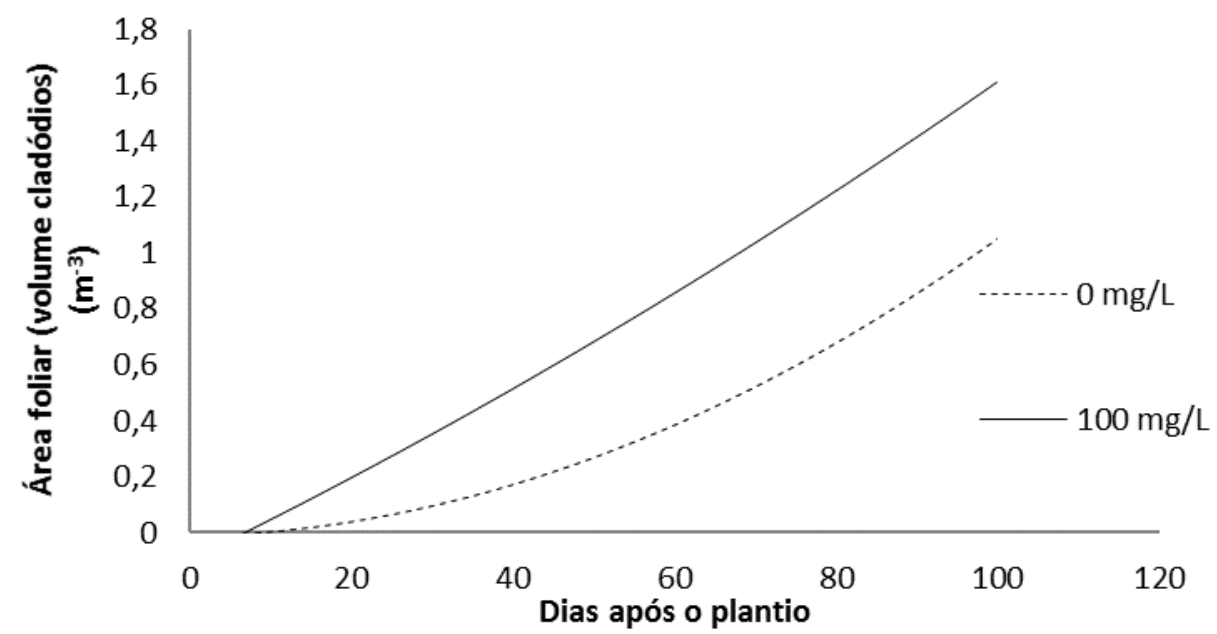

Figura 2. Incremento diário de área foliar (em volume) dos cladódios inoculados com 0 (testemunha) e $100 \mathrm{mg} \cdot \mathrm{L}^{-1}$.

Cultura Agronômica, Ilha Solteira, v.26, n.4, p.657-670, 2017 
Como o cladódio da pitaia é o órgão fotossintetizante o incremente diário em tamanho reflete o investimento da planta nessa função essencial para a maximização da produção de carboidratos. Originalmente de área de sub-bosque, o maior volume de cladódios permite a pitaia interceptar a radiação solar em ambiente sombreado. E a plasticidade do metabolismo ácido das crassuláceas (CAM) do tipo cíclico permite a abertura de estómatos em horas amenas do dia o que reflete em um grande incremento de biomassa o que só é observado em algumas CAM facultativas (PIMENTEL, 1998; ORTIZ-HERNANDEZ et al., 1999).

\section{Taxas de Crescimento}

O gráfico da taxa de crescimento relativo (TCR) das brotações dos cladódios inoculados com BAP encontra-se na Figura 3. Nota-se velocidade inicial de crescimento maior em cladódios da testemunha em relação às estacas tratadas com $100 \mathrm{mg} \cdot \mathrm{L}^{-1}$.

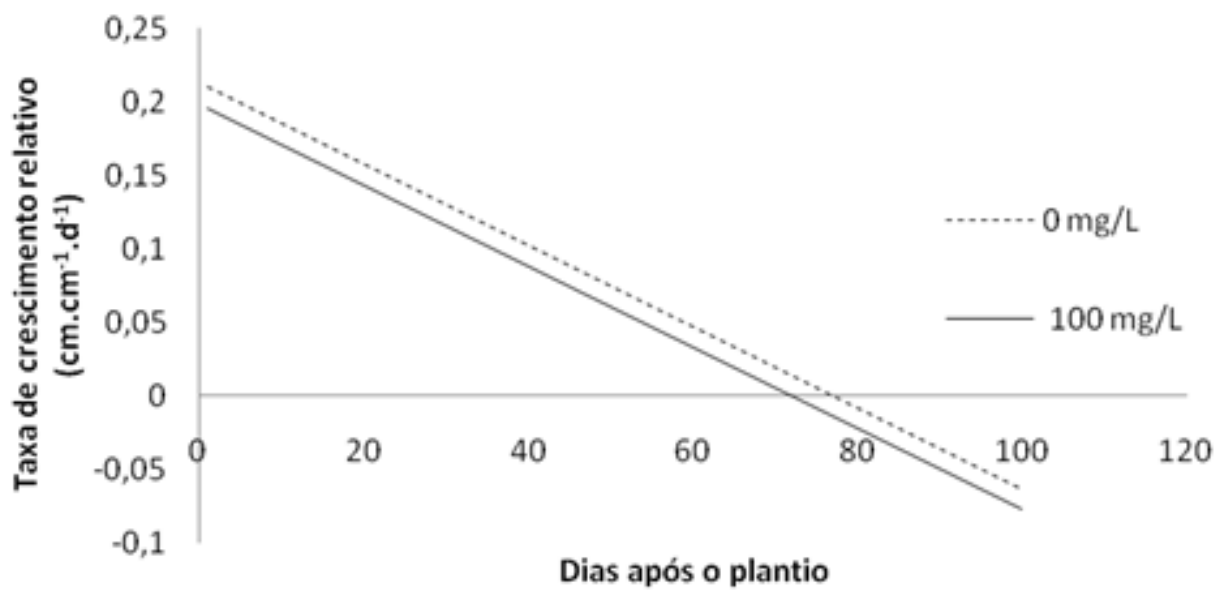

Figura 3. Taxa de crescimento relativo das brotações dos cladódios de pitaia inoculados com 0 (testemunha) e $100 \mathrm{mg} \cdot \mathrm{L}^{-1}$.

Como a TCR neste trabalho exprime o crescimento de cladódios $(\mathrm{cm})$ de pitaia em função do tamanho dos cladódios pré-existentes o crescimento maior absoluto (Figura 4) pode estar associado com o efeito imediato da citocinina no aumento da concentração de clorofila e portando na função fotossintética (PIMENTEL, 1998).

Ainda na Figura 4 nota-se um comportamento díspar entre as taxas das estacas inoculadas com $100 \mathrm{mg} . \mathrm{L}^{-1} \mathrm{e}$ da testemunha. Os cladódios inoculados tiveram taxas máximas aos 55 dias e a testemunha aos 60 dias. As taxas tornaram-se negativas aos 75 DAP (100 mg. $\left.\mathrm{L}^{-1}\right)$ e 79 DAP (testemunha) e as taxas mínimas foram observadas próximo aos 85 dias para o tratamento com $100 \mathrm{mg} . \mathrm{L}^{-1}$ de BAP e 90 dias para a testemunha. 


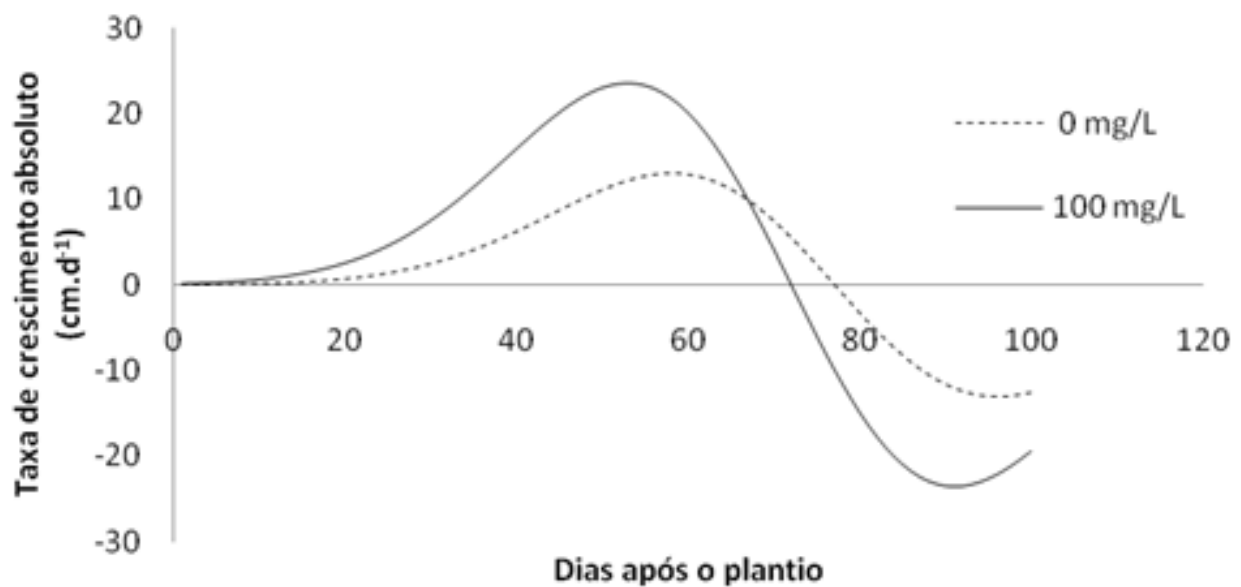

Figura 4. Taxa diária de crescimento absoluto de brotações de estacas de pitaias inoculadas com 0 (testemunha) e 100 mg. $\mathrm{L}^{-1}$ de BAP.

Hunt (1982) cita que com o desenvolvimento do vegetal espera-se uma diminuição nas taxas de crescimento, pois este investe os fotoassimilados em outros órgãos como raízes e aparato reprodutivo ou os tecidos fotossintetizantes tornam-se lignificados perdendo a função de assimilação de $\mathrm{CO}_{2}$ ou mesmo por senescência. Porém, como no presente trabalho as mudas são jovens e só atingiriam a maturidade um ano após a estaquia podemos inferir que tais quedas na TCA foram de fatores extrínsecos e como o manejo relacionado ao crescimento foi controlado (irrigação, controle de ervas, daninhas, pragas e doenças) esperase que esses decréscimos são provocados por algum outro fator como o climático.

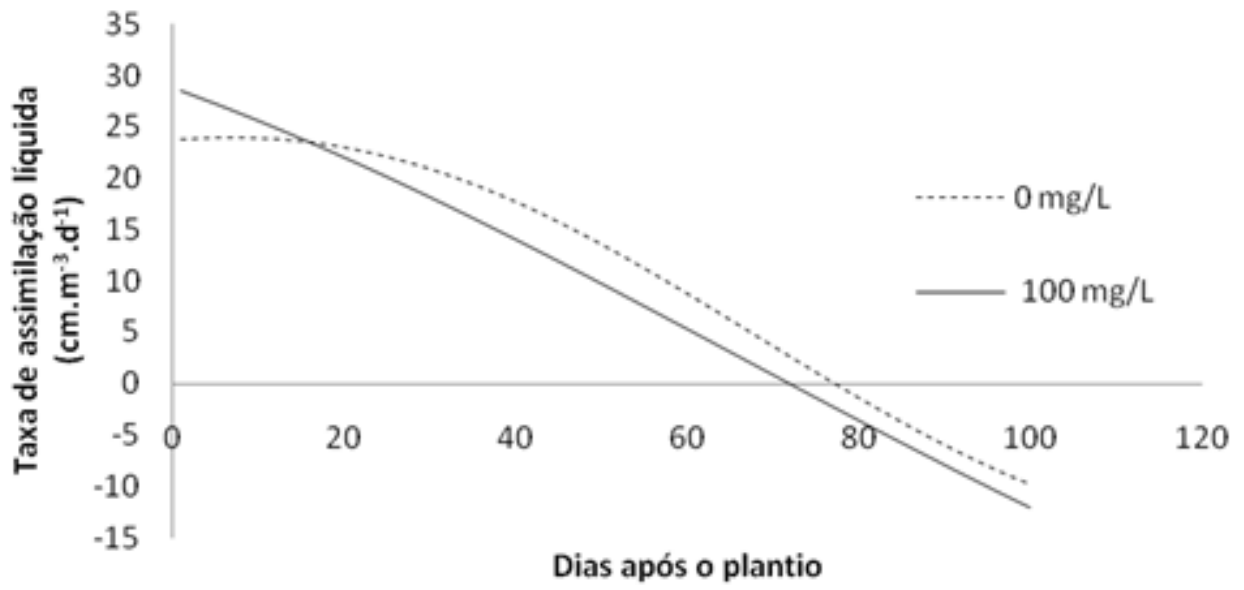

Figura 5. Taxa de Assimilação Líquida diária, das brotações de pitaia inoculadas com 0 (testemunha) e 100mg. $\mathrm{L}^{-1}$ de BAP.

Cultura Agronômica, Ilha Solteira, v.26, n.4, p.657-670, 2017 
O gráfico da taxa de assimilação líquida (TAL) está representado na Figura 5. Esse gráfico mostra que o crescimento observado na TCA até os 60 dias foi acompanhado pelo grande investimento em tecido fotossintetizante nos primeiros 40 dias. Nota-se TAL inicial maior para as estacas inoculadas com BAP em relação à testemunha, refletindo no maior crescimento das brotações desse tratamento. Ainda aos 75 dias DAP para as estacas tratadas com $100 \mathrm{mg} . \mathrm{L}^{-1}$ e 79 dias para o tratamento testemunha nota-se que o saldo fotossintético se torna negativo causado por algum fator extrínseco.

\section{Correlação entre as Taxas de Crescimento e dados Climáticos.}

Não houve correlações significativas entre as taxas de crescimento e os dados climáticos do período, por sua vez, foi observado correlação significativa negativa $(\mathrm{p}<0,001)$ entre as taxas de crescimento e os dados de radiação solar no período das $19 \mathrm{~h}$ (22 h UTC) demonstrado na Tabela 4.

Tabela 4. Coeficientes de correlações simples entre as taxas de crescimento relativo, absoluto e de assimilação líquida das brotações de estacas de pitaia inoculadas com 0 (testemunha) e $100 \mathrm{mg} . \mathrm{L}^{-1}$ de BAP e a radiação solar do período das 19 h (22 h UTC).

\begin{tabular}{lccc}
\hline \multirow{2}{*}{ Tratamentos } & \multicolumn{3}{c}{ Correlações com Radiação Solar Global 19 h $(22 \mathrm{~h} \mathrm{UTC})\left(\mathrm{KJ} / \mathrm{M}^{2}\right)$} \\
\cline { 2 - 4 } & $\begin{array}{c}\text { Taxa de Crescimento } \\
\text { Relativo (TCR) }\end{array}$ & $\begin{array}{c}\text { Taxa de Crescimento } \\
\text { Absoluto (TCA) }\end{array}$ & $\begin{array}{c}\text { Taxa de Assimilação } \\
\text { Líquida (TAL) }\end{array}$ \\
\hline $0 \mathrm{mg} . \mathrm{L}^{-1}$ & $-0,63^{*}$ & $-0,33^{*}$ & $-0,66^{*}$ \\
$100 \mathrm{mg} . \mathrm{L}^{-1}$ & $-0,63^{*}$ & $-0,51^{*}$ & $-0,64^{*}$ \\
\hline
\end{tabular}

* significativo pelo teste $\mathrm{t}(\mathrm{p}<0,001)$

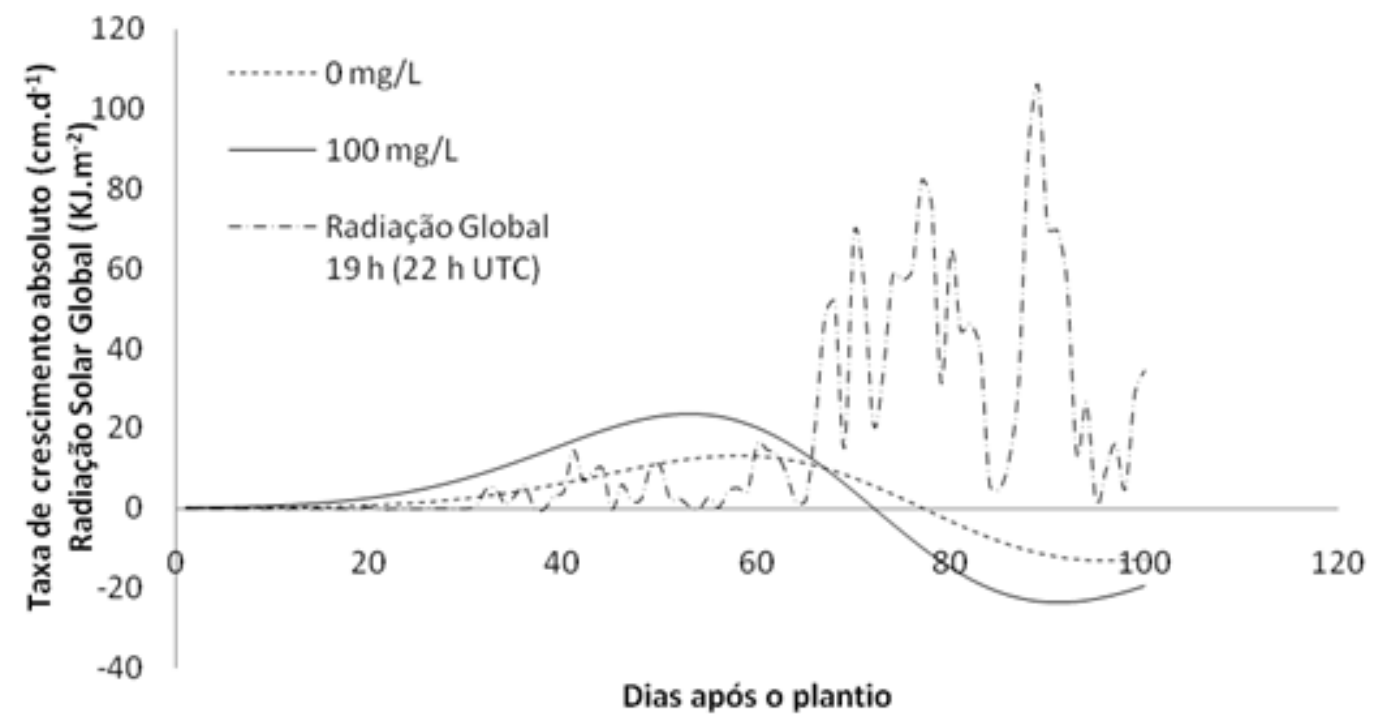

Figura 6. Gráfico da Correlação entre a Radiação Solar $\left(\mathrm{KJ} . \mathrm{m}^{-2}\right)$ no horário 19 h $(22$ h UTC) e Taxa de Crescimento Absoluto de estacas de pitaia inoculadas com 0 (testemunha) e 100 mg.L ${ }^{-1}$ de BAP.

Cultura Agronômica, Ilha Solteira, v.26, n.4, p.657-670, 2017 
As correlações negativas observadas para os dados de radiação solar das 19 horas (22 h UTC), a incidência dos raios solares neste período diminui a produção de fotoassimilados e consequente diminuição nas taxas de crescimento. Cavalcante et al. (2011) e Chang et al. (2016) relatam que a intensidade luminosa é prejudicial à pitaia e que essa frutífera necessita de sombreamento artificial de 50 a $60 \%$ do total da luminosidade incidente sobre a planta pelo menos no período de inicial de crescimento das mudas. A radiação Solar observada então no período das 19 horas ( 22 h UTC) da Figura 6 pode inibir ou adiar a abertura estomática noturna típica de plantas CAM resultando nas menores taxas de crescimento observadas.

As taxas negativas de crescimento absoluto a partir dos 75 DAP (100 mg.L.-1 de BAP) e 79 DAP (testemunha) coincide com o solstício de verão com dias mais longos (noites mais curtas) e ainda se observa que aos 85 e 90 DAP coincide com as maiores radiações do ano e assim as menores taxas de crescimento absoluto o que culminou também com a diminuição das taxas de assimilação líquida (Figura 7) de todos os tratamentos. O decréscimo na fotossíntese observado com a TAL é corroborado pelos resultados de Raveh et al. (2009) que mensuraram mensalmente a fotossíntese por um ano (agosto/2006 a agosto/2007) em $H$. undatus e verificaram o declínio das taxas fotossintéticas deste período em Israel. Jiang et al. (2012) relatam que o fotoperíodo regula a brotação e floração da pitaia como observado neste trabalho com a análise de crescimento e a correlação com a radiação solar desse período das $19 \mathrm{~h}$ (22 h UTC).

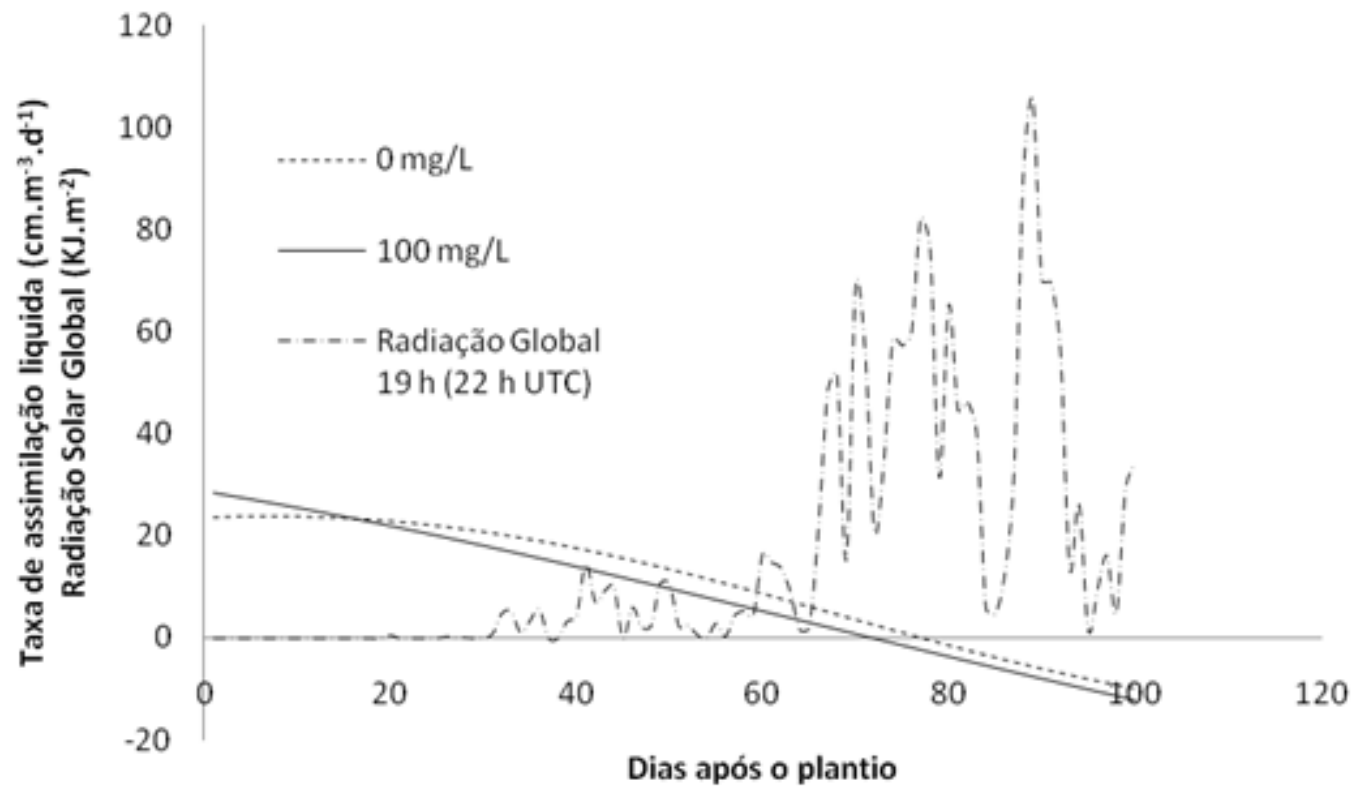

Figura 7. Gráfico da correlação entre a radiação solar (KJ.m² $)$ no horário de 19 h (22 UTC) e a taxa de assimilação líquida de estacas de pitaia inoculadas com 0 (testemunha) e 100 mg.L ${ }^{-1}$ de BAP. 
Esse comportamento pode ser explicado, em tese, pela diminuição do período de abertura estomática dessas plantas CAM com menor assimilação de $\mathrm{CO}_{2}$ atmosférico. Outros processos podem estar envolvidos, pois nesse período do ano que a pitaia emite flores e frutos (MARQUES et al., 2011; SILVA et al., 2015).

Osmond (1978) estudou sobre as fases de regulação do metabolismo CAM e verificou que no momento de transição entre dia e noite as duas enzimas (PEPcase e RUBISCO) estão ativas, fato esse que pode explicar as taxas negativas observadas pelo efeito da insolação nos cactos neste período específico.

Nobel et al. (2006) pesquisou a assimilação de $\mathrm{CO}_{2}$ em $H$. undatus e $S$. Megalanthus (H. Megalanthus) sob condições de seca e altas temperaturas comparados a condições de clima mais ameno e manejo irrigado e relata alteração nas taxas de assimilação fotossintética que alteram o ciclo circadiano de assimilação de $\mathrm{CO}_{2}$ quando a pitaia sofre altas temperaturas (maiores que $40{ }^{\circ} \mathrm{C}$ ) e período de seca ( 8 dias) possivelmente com ação na capacidade da enzima PEPCase e RUBISCO de fixar e se regenerar.

Esses resultados indicam que estudos utilizando a análise quantitativa de crescimento por um ciclo ou ciclos completos produtivos da pitaia podem ajudar a compreender o desenvolvimento dessa frutífera fornecendo informações importantes para o manejo e que estudos do fotoperíodo e possível indução de floração e produção em outras épocas do ano devem considerar esse horário (19 h; 22 h UTC) altamente correlacionado com o desenvolvimento da pitaia.

\section{CONCLUSÃO}

O uso da citocinina 6-benziloaminopurina favoreceu o crescimento das brotações das mudas de $H$. undatus e a radiação solar global do período das 19 horas (22 h UTC) interfere negativamente nas taxas de crescimento das mudas de pitaia.

\section{REFERÊNCIAS BIBLIOGRÁFICAS}

ALMEIDA, E. I. B.; CORRÊA, M. C. M.; CAJAZEIRA, J. P.; QUEIROZ, R. F.; BARROSO, M. M. A.; MARQUES, V. B. Cultivo de Hylocereus sp. com enfoque na propagação vegetativa e adubação mineral. Revista Agroambiente, Boa Vista, v. 10, n. 1, p.65-76, 2016.

ARAÚJO, A. P. Analysis of variance of primary data on plant growth analysis. Pesquisa Agropecuária Brasileira, Brasilia, v. 38, n. 1, p.1-10, 2003.

ARAÚJO, A. P.; ROSSIELLO, R. O. P. Aplicação da análise quantitativa do crescimento vegetal para avaliar a absorção e a utilização de nutrientes. Tópicos em Ciência do Solo, Viçosa, v. 8, n. 1, p.293-323, 2013.

Cultura Agronômica, Ilha Solteira, v.26, n.4, p.657-670, 2017 
BARRUETO CID, L. P. Introdução aos hormônios vegetais. Brasília: Embrapa Recursos Genéticos e Biotecnologia, 2000. 180 p.

BENICASA, M. M. P. Análise de Crescimento de Plantas (noções básicas). Jaboticabal: FUNEP, 2003. 42 p.

CARDOSO, G. D.; AlveS, P. L. C. A.; BELTRÃO, N. E. M.; BARRETO, A. F. Uso de análise de crescimento não destrutivo como ferramenta para a avaliação de cultivares. Revista de Biologia e Ciências da Terra, Aracajú, v. 6, n. 2, p.79-84, 2006.

CAVALCANTE, I. H. L.; MARTINS, A. B. G.; DA SILVA JÚNIOR, G. B.; ROCHA, L. F.; FALCÃO NETO, R.; CAVALCANTE, L. F. Adubação orgânica e intensidade luminosa no crescimento e desenvolvimento inicial da Pitaia em Bom Jesus-PI. Revista Brasileira de Fruticultura, Jaboticabal, v. 33, n. 3, p.970-982, 2011.

CHANG, P. T.; HSIEH, C. C.; JIANG, Y. L. Responses of 'Shih HuoChuan' pitaya (Hylocereus polyrhizus (Weber) Britt.\& Rose) to different degrees of shading nets. Scientia Horticulturae, Amsterdã, v. 198. n. 1, p.154-162, 2016.

EMBRAPA - EMPRESA BRASILEIRA DE PESQUISA AGROPECUÁRIA. Manual de laboratórios: solo, água, nutrição, animal e alimentos. São Carlos: Embrapa Pecuária Sudeste, 2005. 334 p.

HUNT, R. Plant growth curves: The funcional approach to plant growth analisys. London: Edward Arnold, 1982. 248 p.

JIANG, Y. L.; LIAO, Y. Y.; LIN, T. S.; LEE, C. L.; YEN, C. R.; YANG, W. J. The Photoperiod-regulated Bud Formation of Red Pitaya (Hylocereu ssp.). HortScience, Alexandria, v. 47, n. 8, p.1063-1067, 2012.

MARQUES, V. B.; MOREIRA, R.A.; RAMOS, J. D.; ARAUJO, N. A.; CRUZ, M. C. M. Tamanho de cladódios na produção de mudas de pitaia vermelha. Revista Caatinga, Mossoró, v. 24, n. 4, p.50-54, 2011.

MARQUES, V. B.; MOREIRA, R. A.; RAMOS, J. D.; ARAUJO, N. A.; CRUZ, M. C. M. Profundidade de plantio e dominância apical na estaquia da pitaia vermelha. Semina: Ciências Agrárias, Londrina, v. 33, n. 6, p.2091-2098, 2012.

MIZRAHI, Y. Vine-cacti pitayas: The new crops of the World. Revista Brasileira de Fruticultura, Jaboticabal, v. 36, n. 1, p.124-138, 2014.

NERD, A.; SITRIT, Y.; KAUSHIK, R. A.; MIZRAHI, Y. High summer temperatures inhibit flowering in vine pitaya crops (Hylocereus spp.). Scientia Horticulturae, Amsterdã, v. 96, n. 1, p.343-350, 2002.

NOBEL, P. S. Parenchyma-chlorenchyma water movement during drought for the hemiepiphytic cactus Hylocereus undatus. Annals of Botany, Oxford, v. 97, n. 1, p.469474, 2006.

Cultura Agronômica, Ilha Solteira, v.26, n.4, p.657-670, 2017 
NUNES, E. N.; SOUSA, A. S. B.; LUCENA, C. M.; SILVA, S. M.; LUCENA, R. F. P.; ALVES, C. A. B.; ALVES, R. E. Pitaia (Hylocereus ssp.): Uma revisão para o Brasil. Gaia Scientia, João Pessoa, v. 8, n. 1, p.90-98, 2014.

ORTIZ-HERNANDEZ, Y. D.; LIVERA, M. M.; COLINAS, M. T. B.; CARRILOSALAZAR, J. A. Estrés hídrico e intercambio de $\mathrm{CO}_{2}$ de la pitahaya (Hylocereus undatus). Agrociencia, Texcoco, v. 33, n. 4, p.397-405, 1999.

ORTIZ-HERNANDEZ, Y. D.; CARRILO - SALAZAR, J. A. Pitaia (Hylocereus spp.): uma revisão. Comunicata Scientiae, Bom Jesus, v. 3, n. 4, p.220-237, 2012.

PEDUlA, R. O.; SCHUlTZ, N.; MONTEIRO, R. C.; PEREIRA, W.; ARAÚJO, A. P.; URQUIAGA, S.; REIS, V. M. Growth analysis of sugarcane inoculated with diazotrophic bacteria and nitrogen fertilization. African Journal of Agricultural Research, Niger, v. 11, n. 30, p.2786-2795, 2016.

PIMENTEL, C. Metabolismo do carbono na Agricultura Tropical. Seropédica: Edur, 1998. $150 \mathrm{p}$.

RAVEH, E.; NERD, A.; MIZRAHI, Y. Responses of two hemiepiphytic fruit crop cacti to different degrees of shade. Scientia Horticulturae, Amsterdam, v. 73, n. 1, p.151-164, 2009.

OSMOND, C. B. Crassulacean acid metabolism: a curiosity in context. Annual Review of Plant Physiology, Palo Alto, v. 29, n. 1, p.379-414, 1978.

SILVA, A. C. C.; CAVAlLARI, L. L.; SABIÃO, R. R.; MARTINS, A. B. G. Fenologia reprodutiva da pitaya vermelha em Jaboticabal, SP. Ciencia Rural, Santa Maria, v. 45, n. 4, p.585-590, 2015.

SILVA, A. C. C.; SABIÃO, R. R., CHIAMOLERA, F. M., SEGANTINI, D. M.; MARTINS, A. B. G. Morphological traits as tool to verify genetic variability of interspecific dragon fruit hybrids. Revista Brasileira de Fruticultura, Jaboticabal, v. 39, n. 1, p.1-8, 2017.

SHIMOMURA, T.; FUJIHARA, K. Stimulation of axillary shoot formation of cuttings of Hylocereus trigonus (Cactaceae) by pre-soaking in benzyladenine solution. Scientia Horticulturae, Amsterdã, v. 13, n. 3, p.289-296, 1980.

TAIZ, L.; ZEIGER, E. Fisiologia Vegetal. 3. ed. Porto Alegre: Artmed, 2004. 722 p.

ZEE, F.; YEN, C. R.; NISHINA, M. Pitaya (Dragon Fruit, Strawberry Pear). Fruits and Nuts, Hawaii, v. 3, n. 1, p.1-3, 2004.

Cultura Agronômica, Ilha Solteira, v.26, n.4, p.657-670, 2017 